\title{
On Berinde's method for comparing iterative processes
}

\section{Constantin Zălinescu ${ }^{1 *}$ (D}

\begin{abstract}
In the literature there are several methods for comparing two convergent iterative processes for the same problem. In this note we have in view mostly the one introduced by Berinde in (Fixed Point Theory Appl. 2:97-105, 2004) because it seems to be very successful. In fact, if IP1 and IP2 are two iterative processes converging to the same element, then IP1 is faster than IP2 in the sense of Berinde. The aim of this note is to prove this almost obvious assertion and to discuss briefly several papers that cite the mentioned Berinde's paper and use his method for comparing iterative processes.
\end{abstract}

MSC: 41 A99

Keywords: Faster convergence; Better convergence; Berinde's method for comparing iterative processes

\section{Introduction}

In the literature there are several methods for comparing two convergent iterative processes for the same problem. In this note we have in view mostly the one introduced by Berinde in [15, Definition 2.7] because it seems to be very successful. This was pointed out by Berinde himself in [18]: "This concept turned out to be a very useful and versatile tool in studying the fixed point iterative schemes and hence various authors have used it". However, it was pointed out by Popescu, using [75, Example 3.4], that Berinde's method is not consistent. The inconsistency of Berinde's method is indirectly mentioned also by Qing and Rhoades in [77, p. 2] by providing a very simple counterexample in $\mathbb{R}$ to $[13$, Theorem 2.1]. ${ }^{\text {a }}$ Moreover, referring to Berinde's method, Phuengrattana and Suantai say in [73, p. 218]: "It seems not to be clear if we use above definition for comparing the rate of convergence". In fact, if IP1 and IP2 are two (arbitrary) iterative processes converging to the same element, then IP1 is faster than IP2 (and vice-versa) in the sense of Berinde [15, Definition 2.7].

The aim of this note is to prove this almost obvious assertion and to discuss briefly several papers that cite [15] and refer to Berinde's method for comparing iterative processes.

(c) The Author(s) 2021. This article is licensed under a Creative Commons Attribution 4.0 International License, which permits use, sharing, adaptation, distribution and reproduction in any medium or format, as long as you give appropriate credit to the original author(s) and the source, provide a link to the Creative Commons licence, and indicate if changes were made. The images or other third party material in this article are included in the article's Creative Commons licence, unless indicated otherwise in a credit line to the material. If material is not included in the article's Creative Commons licence and your intended use is not permitted by statutory regulation or exceeds the permitted use, you will need to obtain permission directly from the copyright holder. To view a copy of this licence, visit http://creativecommons.org/licenses/by/4.0/. 


\section{Definitions and the main assertion}

First, we quote from $[15, \mathrm{pp} .99,100]$ the text containing the definitions which we have in view; these are reproduced in many papers from our bibliography.

Definition 2.5. Let $\left\{a_{n}\right\}_{n=0}^{\infty},\left\{b_{n}\right\}_{n=0}^{\infty}$ be two sequences of real numbers that converge to $a$ and $b$, respectively, and assume that there exists $l=\lim _{n \rightarrow \infty}\left|\frac{a_{n}-a}{b_{n}-b}\right|$.

(a) If $l=0$, then it can be said that $\left\{a_{n}\right\}_{n=0}^{\infty}$ converges faster to $a$ than $\left\{b_{n}\right\}_{n=0}^{\infty}$ to $b$.

(b) If $0<l<\infty$, then it can be said that $\left\{a_{n}\right\}_{n=0}^{\infty}$ and $\left\{b_{n}\right\}_{n=0}^{\infty}$ have the same rate of convergence.

Suppose that for two fixed point iteration procedures $\left\{u_{n}\right\}_{n=0}^{\infty}$ and $\left\{v_{n}\right\}_{n=0}^{\infty}$, both converging to the same fixed point $p$, the error estimates

$$
\begin{aligned}
& \left\|u_{n}-p\right\| \leq a_{n}, \quad n=0,1,2, \ldots \\
& \left\|v_{n}-p\right\| \leq b_{n}, \quad n=0,1,2, \ldots
\end{aligned}
$$

are available, where $\left\{a_{n}\right\}_{n=0}^{\infty}$ and $\left\{b_{n}\right\}_{n=0}^{\infty}$ are two sequences of positive numbers (converging to zero).

Then, in view of Definition 2.5, we will adopt the following concept.

Definition 2.7. Let $\left\{u_{n}\right\}_{n=0}^{\infty}$ and $\left\{v_{n}\right\}_{n=0}^{\infty}$ be two fixed point iteration procedures that converge to the same fixed point $p$ and satisfy (2.7) and (2.8), respectively. If $\left\{a_{n}\right\}_{n=0}^{\infty}$ converges faster than $\left\{b_{n}\right\}_{n=0}^{\infty}$, then it can be said that $\left\{u_{n}\right\}_{n=0}^{\infty}$ converges faster than $\left\{v_{n}\right\}_{n=0}^{\infty}$ to $p$.

Practically, the text above is reproduced in [18, pp. 30,31], getting in this way Definitions 1.1 and 1.2. The only differences are: "(2.7)" and "(2.8) are available, where" are replaced by "(1.7)" and "(1.8) are available (and these estimates are the best ones available), where", respectively.

Immediately after [18, Definition 1.2$]$ it is said:

This concept turned out to be a very useful and versatile tool in studying the fixed point iterative schemes and hence various authors have used it, see [1] - [5], [18], [22], [23], [28], [32]-[34], [37]-[41], [40], [43]-[46], [55]-[57], [66], [68]-[72], [74], [78][81], to cite just an incomplete list. ${ }^{\text {b }}$

Note that Definition 9.1 from [16] is equivalent to Definition 2.5 from [15]; replacing $u_{n}, v_{n}, p,\left\|u_{n}-p\right\|$, and $\left\|v_{n}-p\right\|$ with $x_{n}, y_{n}, x^{*}, d\left(x_{n}, x^{*}\right)$, and $d\left(y_{n}, x^{*}\right)$ in (2.7), (2.8), and Definition 2.7 from [15], one obtains relations (5), (6) from [16, p. 201] and an equivalent formulation of [16, Definition 9.2], respectively. Note that these definitions from Berinde's book [16] are presented in the lecture [17].

Because of the parentheses in "(converging to zero)" in the preamble of [15, Definition 2.7] (and [16, Definition 9.2], [18, Definition 1.2]), the convergence to 0 of $\left(a_{n}\right)$ and $\left(b_{n}\right)$ seems to be optional. This is probably the reason for the absence of this condition in [29, p. 3]; note that $\left(a_{n}\right)$ is a constant sequence in [90].

In the next result we use the version for metric spaces of [15, Definition 2.7] (see [16, Definition 9.2]).

Proposition 1 Let $(X, d)$ be a metric space and $\left(x_{n}\right)_{n \geq 1},\left(y_{n}\right)_{n \geq 1}$ be two sequences from $X$ converging to $x^{*} \in X$. Then $\left(x_{n}\right)$ converges faster than $\left(y_{n}\right)$ to $x^{*}$. 
Proof For each $n \geq 1$, let us consider

$$
0<a_{n}:=d\left(x_{n}, x^{*}\right)+d\left(y_{n}, x^{*}\right)+\frac{1}{n}, \quad 0<b_{n}:= \begin{cases}\sqrt{a_{n}} & \text { if } a_{n} \leq 1, \\ d\left(y_{n}, x^{*}\right) & \text { otherwise }\end{cases}
$$

It follows that $a_{n} \rightarrow 0, b_{n} \rightarrow 0$,

$$
d\left(x_{n}, x^{*}\right) \leq a_{n}, \quad d\left(y_{n}, x^{*}\right) \leq b_{n}, \quad \forall n \geq 1,
$$

and $a_{n} / b_{n}=\sqrt{a_{n}}$ for sufficiently large $n$; it follows that $\lim _{n \rightarrow \infty} a_{n} / b_{n}=\lim _{n \rightarrow \infty} \sqrt{a_{n}}=0$. Therefore, $\left(x_{n}\right)$ converges faster to $x^{*}$ than $\left(y_{n}\right)$ does.

From our point of view, the preceding "result" shows that Berinde's notion of rapidity for fixed point iterative schemes, recalled above, is not useful, even if Berinde in [18, p. 35] claims that "Of all concepts of rapidity of convergence presented above for numerical sequences, the one introduced by us in Definition 1.2 [14] appears to be the most suitable in the study of fixed point iterative methods". Berinde (see [18, p. 36]) mentions that he "tacitly admitted in Definition 1.2 that the estimates (1.7) and (1.8) taken into consideration are the best possible". Clearly, "the estimates are the best ones available" and "the estimates ... are the best possible" are very different in meaning. ${ }^{c}$

Of course, the best possible estimates in relations (1.7) and (1.8) from [18] (that is, in relations (2.7) and (2.8) from [15] recalled above) are

$$
a_{n}:=\left\|u_{n}-p\right\|, \quad b_{n}:=\left\|v_{n}-p\right\| \quad(n \geq 0) .
$$

Assuming that $d\left(x_{n}, x^{*}\right) \rightarrow 0$, getting (better) upper estimates for $d\left(x_{n}, x^{*}\right)$ depends on the proof, including the author's ability to majorize certain expressions. Surely, the best available estimates are exactly those obtained by the authors in their proofs.

The use of Berinde's method for comparing the speeds of convergence is very subjective. It is analogue to deciding that $a / b \leq c / d$ knowing only that $0<a \leq c$ and $0<b \leq d$ !

Taking $a_{n}$ and $b_{n}$ defined by (1) in [15, Definition 2.7], one obtains Definition 3.5 of Popescu from [75]. ${ }^{\mathrm{d}}$ Popescu's definition is used explicitly by Rhoades and Xue (see [81, p. 3]), but they wrongly attribute it to [15]; this attribution is wrong because [75, Definition 3.5] reduces to [15, Definition 2.5] only in the case in which the involved normed vector space is $\mathbb{R}$. Note that Rhoades knew about Popescu's definition because [75] is cited in $[77$, p. 2].

Notice that Popescu's definition is extended to metric spaces by Berinde, Khan, and Păcurar in [20, p. 32], as well as by Fukhar-ud-din and Berinde in [31, p. 228]; also observe that Popescu's paper [75] is not cited in [20] and [31].

Even if in [15] it is not defined when two iteration schemes have the same rate of convergence, Dogan and Karakaya obtained that "the iteration schemes $\left\{k_{n}\right\}_{n=0}^{\infty}$ and $\left\{l_{n}\right\}_{n=0}^{\infty}$ have the same rate of convergence to $p$ of $\wp$ " in [27, Theorem 2.4]; the proof of [27, Theorem 2.4] is based on the fact that they found the same upper estimates for $\left\|k_{n+1}-p\right\|$ and $\left\|l_{n+1}-p\right\|$ when $l_{0}=k_{0}$.

Accepting such an argument and taking $a_{n}:=b_{n}:=d\left(x_{n}, x^{*}\right)+d\left(y_{n}, x^{*}\right)+\frac{1}{n}$ in the proof of Proposition 1, one should obtain that any pair of sequences $\left(x_{n}\right)_{n \geq 1},\left(y_{n}\right)_{n \geq 1} \subset(X, d)$ with the same limit $x^{*} \in X$ have the same rate of convergence. 
Recall that Rhoades in $[80$, pp. 742,743$]$ says that having " $\left\{x_{n}\right\},\left\{z_{n}\right\}$ two iteration schemes which converge to the same fixed point $p$, we shall say that $\left\{x_{n}\right\}$ is better than $\left\{z_{n}\right\}$ if $\mid x_{n}$ $p|\leq| z_{n}-p \mid$ for all $n$; ; having in view the previous definition and [15, Example 2.8], Berinde claims that "The previous example shows that Definition 2.7 introduces a sharper concept of rate of convergence than the one considered by Rhoades [11]". In this context we propose the following definition.

Definition 2 Let $(X, d)$ be a metric space, and let $\left(x_{n}\right)_{n \geq 1},\left(y_{n}\right)_{n \geq 1} \subset(X, d)$, and $x, y \in X$ be such that $x_{n} \rightarrow x, y_{n} \rightarrow y$. One says that $\left(x_{n}\right)$ converges better to $x$ than $\left(y_{n}\right)$ to $y$ if there exists some $\alpha>0$ such that $d\left(x_{n}, x\right) \leq \alpha d\left(y_{n}, y\right)$ for sufficiently large $n$; one says that $\left(x_{n}\right)$ and $\left(y_{n}\right)$ have the same rate of convergence if $\left(x_{n}\right)$ converges better to $x$ than $\left(y_{n}\right)$ to $y$, and $\left(y_{n}\right)$ converges better to $y$ than $\left(x_{n}\right)$ to $x$.

Using the conventions $\frac{0}{0}:=1$ and $\frac{\alpha}{0}:=\infty$ for $\alpha>0$, [( $\left.x_{n}\right)$ converges better to $x$ than $\left(y_{n}\right)$ to $\left.y\right]$ if and only if $\lim \sup _{n \rightarrow \infty} \frac{d\left(x_{n}, x\right)}{d\left(y_{n}, y\right)}<\infty$; consequently, [( $\left.x_{n}\right)$ and $\left(y_{n}\right)$ have the same rate of convergence] (in the sense of Definition 2) if and only if $0<\liminf _{n \rightarrow \infty} \frac{d\left(x_{n}, x\right)}{d\left(y_{n}, y\right)} \leq$ $\lim \sup _{n \rightarrow \infty} \frac{d\left(x_{n}, x\right)}{d\left(y_{n}, y\right)}<\infty$. $^{\mathrm{e}}$

Example 3 Consider the sequences $\left(x_{n}\right)_{n \geq 1},\left(y_{n}\right)_{n \geq 1} \subset \mathbb{R}$ defined by

$$
x_{n}:=\left\{\begin{array}{ll}
n^{-1} & \text { if } n \text { is odd, } \\
(2 n)^{-1} & \text { if } n \text { is even, }
\end{array} \quad y_{n}:= \begin{cases}(2 n)^{-1} & \text { if } n \text { is odd } \\
n^{-1} & \text { if } n \text { is even }\end{cases}\right.
$$

Clearly $\lim _{n \rightarrow \infty} x_{n}=\lim _{n \rightarrow \infty} y_{n}=0$, and it is very natural to consider that they have the same rate of convergence; this is confirmed using Definition 2. It is obvious that neither $\left(x_{n}\right)$ is better (faster) than $\left(y_{n}\right)$, nor $\left(y_{n}\right)$ is better (faster) than $\left(x_{n}\right)$ in the senses of Rhoades [80, pp. 742, 743], or Berinde [15, Definition 2.5], or Popescu [75, Definition 3.5], or Berinde, Khan, and Păcurar [20, p. 32], or Fukhar-ud-din and Berinde [31, p. 228].

\section{Remarks on the use of Berinde and Popescu's notions in papers citing [15]}

Practically, all the papers mentioned in the sequel were found on the internet when searching, with Google Scholar, for the works citing Berinde's article [15].

First we give the list of articles, mentioning their authors and results, in which Berinde's Definition 2.7 from [15] is used (even if not said explicitly):

Berinde and Berinde-[19, Theorem 3.3]; Babu and Prasad-[13, Theorem 2.1] and [14, Theorems 3.1, 3.3]; Olaleru-[69, Theorem 1] and [70, Theorems 1, 2]; ${ }^{\mathrm{f}}$ Sahu-[82, Theorem 3.6]; Akbulut and Özdemir-[5, Theorem 2.3]; Hussain et al._[43, Theorems 18, 19]; Karahan and Ozdemir-[49, Theorem 1]; Abbas and Nazir-[2, Theorem 3]; Gürsoy and Karakaya-[39, Theorem 3]; Kadioglu and Yildirim-[47, Theorem 5]; Karakaya et al.[52, Theorem 3] $]^{\mathrm{g}}$ and [53, Theorem 2.2]; Kumar-[59, Theorem 3.1]; Öztürk Çeliker-[71, Theorem 8]; Thakur et al.-[88, Theorem 2.3 $]^{\mathrm{h}}$ and [87, Theorem 3.1]; Chugh et al.-[23, Theorem 3.1] and [24, Theorem 13]; Fathollahi et al.-[29, Propositions 3.1, 3.2, Theorems 3.1, 4.1-4.4, Lemmas 3.1-3.4]; Gursoy-[35, Theorem 3]; Jami and Abed-[46, Theorems 3.1-3.4]; Yadav-[93, Example 2]; Abed and Abbas, [3, Theorem (3.8)]; Asaduzzaman et al.-[11, Theorem 3.3]; Mogbademu-[66, Theorem 2.1]; Rani and Jyoti[79, Theorem 13]; Sahu et al.-[83, Theorem 4.1]; Sintunavarat and Pitea-[86, The- 
orem 2.1]; Verma et al.-[90]; ${ }^{\mathrm{i}}$ Alecsa-[8, Theorems 3.1, 3.3-3.12]; Karakaya et al.[50, Theorem 2.4]; Okeke and Abbas-[68, Proposition 2.1]; Sharma and Imdad-[84, Proposition 4.9]; Yildirim and Abbas-[95, Theorem 2]; Abass et al.-[1, Remark 2]; Akhtar and Khan-[6, Theorem 3.1-3.3]; Alagoz et al.-[7, Theorem 2.1]; Dogan-[25, Theorem 3.3.1]; Fathollahi and Rezapour-[30, Propositions 2.1-2.3, 3.1, Theorem 3.2]; Garodia and Uddin-[32, Theorem 3.1]; Hussain et al.-[45, Theorem 3.4]; Kumar and Chauhan-[60, Theorems 1, 2]; Piri et al. [74, Lemmas 3.1, 3.2, Theorem 3.3]; Yildirim[94, Theorem 2], Asaduzzaman and Ali-[10, Theorem 3.3], Ertürk and Gürsoy-[28, Theorem 2.3]; Gürsoy et al._[37, Theorem 6]; Kumar and Chugh-[61, Theorem 2.2]; Malik and Choudhary-[64, Theorem 6]; Mebawondu and Mewomo-[65, Theorem 3.2]; Okeke-[67, Theorem 3.3]; Aibinu and Kim—[4, Theorem 3.2]; Garodia and Uddin - [33, Theorem 3.1] and [34, Theorem 3.1]; Gürsoy et al.-[40, Theorem 2.3].

As mentioned in Sect. 2, Dogan and Karakaya obtained that "the iteration schemes $\left\{k_{n}\right\}_{n=0}^{\infty}$ and $\left\{l_{n}\right\}_{n=0}^{\infty}$ have the same rate of convergence to $p$ of $\wp$ " in [27, Theorem 2.4] because they found the same upper estimates for $\left\|k_{n+1}-p\right\|$ and $\left\|l_{n+1}-p\right\|$ when $l_{0}=k_{0}$ (see [27, p. 156]).

It is worth repeating that Popescu (in [75]) recalls [15, Definition 2.7], mentions its inconsistency, introduces his direct comparison of iterative processes in [75, Definition 3.5], and uses this definition in [75, Theorem 3.7].

Other papers in which [75, Definition 3.5] is used, without citing it (but possibly recalling [15, Definition 2.5 or/and Definition 2.7]), are: Xue-[92, Theorems 2.1, 2.2]; Rhoades and Xue-[81, Theorems 2.1, 2.2, 3.1, 3.2]; Thong-[89, Theorems 2.1, 2.3, 2.5]; Alotaibi et al.-[9, Theorem 3.1]; Hussain et al.-[43, Theorems 14-17]; Phuengrattana and Suantai-[73, Theorems 2.4, 2.6]; Khan et al.-[55, Theorem 3.1]; Fukhar-ud-din and Berinde-[31, Theorems 2.5, 2.7]; Gürsoy-[36, Theorem 2.4]; Khan et al.-[54, Theorem 3]; Gürsoy et al.-[41, Theorem 2.3]; Kosol-[57, Theorem 2.2]; Pansuwan and Sintunavarat-[72, Theorem 3.7]; Atalan and Karakaya-[12, Theorem 3.3]; Ertürk and Gürsoy-[28, Theorem 2.3]; Kumam et al.—[58, Theorems 3.4, 3.5]; Gürsoy et al._[38, Theorem 4].

It is also worth noticing that by taking simple examples in $\mathbb{R}$, Rafiq et al.-[78, Example 11]; Hussain et al._[44, Example 9]; Chugh et al._[22, Example 4.1]; Hussain et al.[42, Example 3.1, 3.2]; Kang et al._[48, Example 11]; Karakaya et al.-[51, Example 4]; Kumar et al.-[63, Example 9]; Doğan and Karakaya-[26, Example 10]; Prasad and Goyal[76, Example 2.1]; Chauhan et al.-[21, Example 3.1]; Sintunavarat-[85, Example 13]; Wahab and Rauf-[91, Example 11, Remarks 12-17] "prove" that certain iteration processes are faster than others.

Final remark I wish to point out that this paper is not about the correctness of the results in the cited papers; I did not check the proofs of the results. My aim is to emphasize again, as Popescu [75] and Phuengrattana and Suantai [73] did, that Berinde's method is inconsistent, and so what is obtained using it is useless from my point of view. The other remarks mainly concern wrong attributions of notions as well as the fact that one cannot claim the validity of general assertions using some examples. 
Funding

There is no funding for this research.

\section{Abbreviations}

Not applicable (et al. is found in the dictionaries).

\section{Availability of data and materials}

Not applicable.

\section{Competing interests}

The author declares that he has no competing interests.

\section{Authors' contributions}

The author read and approved the final manuscript.

\section{Endnotes}

a Note that Berinde's paper [15] is not cited in [77]; see also [18, Remark 3.2].

b Throughout this paper the references mentioned in the quoted texts are those in the works from where the texts are taken.

c Among the 35 papers from our bibliography published in the period 2017-2020, our reference [18] is mentioned only in [28, 37, 38], and [40]. However, [15, Definition 2.7] is used in [28, 37], and [40] without any mention that the obtained estimates are the best possible.

d Of course, when $(X,\|\cdot\|)$ is $(\mathbb{R},|\cdot|)$, Definition 3.5 of Popescu [75] reduces to Definition 2.5(a) of Berinde [15] when $a=b$.

e This manner of comparing the rate of convergence for sequences of real numbers is attributed to Knopp [56] in [41, Definition 1.2]; a more precise presentation of this topic is done in [18, p. 34].

f Kumar (see [62, p. 1320]) shows that [70, Theorem 2] "is not consistent" by using [75, Definition 3.5] and a simple example in $\mathbb{R}$.

9 Note that [52, Definition 1] is [15, Definition 2.5 (a)] for " $\left\{a_{n}\right\}_{n=0}^{\infty}$ and $\left\{b_{n}\right\}_{n=0}^{\infty}$ two sequences of real numbers with limits $a$ and b respectively", but in the proof of [52, Theorem 3] one uses [15, Definition 2.7]. Similar remarks are valid for [53, Definition 1.1, Theorem 2.2], [50, Definition 1.4, Theorem 2.4], [84, Definition 1.11, Proposition 4.9.].

h In $[88$, p. 3] one appreciates that "In recent years, Definition 2.2 has been used as a standard tool to compare the fastness of two fixed point iterations", Definition 2.2 being [15, Definition 2.7].

i See estimates (23) and (24), as well as the very strange arguments to get the conclusion on page SMC_2016 001606

j Note the strange quantity $\left\|\frac{\mathrm{JN}_{n+1}-p}{\mathrm{JI} \mathrm{I}_{n+1}-p}\right\|$, the numerator and denominator being in $(X,\|\cdot\|)$ "an arbitrary Banach space".

\section{Publisher's Note}

Springer Nature remains neutral with regard to jurisdictional claims in published maps and institutional affiliations.

Received: 8 September 2020 Accepted: 25 November 2020 Published online: 01 February 2021

\section{References}

1. Abass, H.A., Mebawondu, A.A., Mewomo, O.T.: Some results for a new three steps iteration scheme in Banach spaces. Bull. Transilv. Univ. Braşov Ser. III 11(2), 1-18 (2018)

2. Abbas, M., Nazir, T.: A new faster iteration process applied to constrained minimization and feasibility problems. Mat. Vesn. 66(2), 223-234 (2014)

3. Abed, S.S., Abbas, R.F.: S-iteration for general quasi multi valued contraction mappings. Int. J. Appl. Math. Stat. Sci. 5(4), 9-22 (2016)

4. Aibinu, M.O., Kim, J.K.: On the rate of convergence of viscosity implicit iterative algorithms. Nonlinear Funct. Anal. Appl. 25(1), 135-152 (2020)

5. Akbulut, S., Özdemir, M.: Picard iteration converges faster than Noor iteration for a class of quasi-contractive operators. Chiang Mai J. Sci. 39(4), 688-692 (2012)

6. Akhtar, Z., Khan, M.A.A.: Rates of convergence for a class of generalized quasi contractive mappings in Kohlenbach hyperbolic spaces. arXiv:1802.09773v1 (2018)

7. Alagoz, O., Gunduz, B., Akbulut, S.: Numerical reckoning fixed points for Berinde mappings via a faster iteration process. Facta Univ., Ser. Math. Inform. 33(2), 295-305 (2018)

8. Alecsa, C.D.: On new faster fixed point iterative schemes for contraction operators and comparison of their rate of convergence in convex metric spaces. Int. J. Nonlinear Anal. Appl. 8(1), 353-388 (2017)

9. Alotaibi, A., Kumar, V., Hussain, N.: Convergence comparison and stability of Jungck-Kirk-type algorithms for common fixed point problems. Fixed Point Theory Appl. 2013, 173 (2013)

10. Asaduzzaman, M., Ali, M.Z.: On convergence, stability and data dependence of four-step implicit fixed point iterative scheme for contractive-like operators in convex metric spaces. Glob. J. Pure Appl. Math. 15(3), 279-304 (2019)

11. Asaduzzaman, M., Khatun, M.S., Ali, M.Z.: On new three-step iterative scheme for approximating the fixed points of non-expansive mappings. JP J. Fixed Point Theory Appl. 11(1), 23-53 (2016)

12. Atalan, Y., Karakaya, V.: Obtaining new fixed point theorems by using generalized Banach-contraction principle. J. Inst. Sci. Technol. 35(3), 34-45 (2019)

13. Babu, G.V.R., Prasad, K.V.: Mann iteration converges faster than Ishikawa iteration for the class of Zamfirescu operators. Fixed Point Theory Appl. 2006, Article ID 49615 (2006). Erratum ibid. 2007, Article ID 97986 (2007)

14. Babu, G.V.R., Prasad, K.V.: Comparison of fastness of the convergence among Krasnoselskij, Mann, and Ishikawa iterations in arbitrary real Banach spaces. Fixed Point Theory Appl. 2006, Article ID 35704 (2006) 
15. Berinde, V: Picard iteration converges faster than Mann iteration for a class of quasi-contractive operators. Fixed Point Theory Appl. 2, 97-105 (2004)

16. Berinde, V.: Iterative Approximation of Fixed Points. Springer, Berlin (2007)

17. Berinde, V: Iterative approximation of fixed points (Approximation itérative des points fixes). CNRS, GT Méthodes Numériques (18 Juin 2007)

18. Berinde, $\mathrm{V}:$ On a notion of rapidity of convergence used in the study of fixed point iterative methods. Creative Math. Inform. 25(1), 29-40 (2016)

19. Berinde, V., Berinde, M.: The fastest Krasnoselskij iteration for approximating fixed points of strictly pseudo-contractive mappings. Carpath. J. Math. 21(1-2), 13-20 (2005)

20. Berinde, V., Khan, A.R., Păcurar, M.: Analytic and empirical study of the rate of convergence of some iterative methods. J. Numer. Anal. Approx. Theory 44(1), 25-37 (2015)

21. Chauhan, S.S., Utreja, K., Imdad, M., Ahmadullah, M.: Strong convergence theorems for a quasi contractive type mapping employing a new iterative scheme with an application. Honam Math. J. 39(1), 1-25 (2017)

22. Chugh, R., Kumar, V., Kumar, S.: Strong convergence of a new three step iterative scheme in Banach spaces. Am. J. Comput. Math. 2, 345-357 (2012)

23. Chugh, R., Malik, P., Kumar, V:: On analytical and numerical study of implicit fixed point iterations. Cogent Math. 2, Article ID 1021623 (2015)

24. Chugh, R., Malik, P., Kumar, V.: On a new faster implicit fixed point iterative scheme in convex metric spaces. J. Funct. Spaces 2015, Article ID 905834 (2015)

25. Doğan, K.: Daha hizli Mann sabit nokta yinelemesi üzerine bir çalisma. AKU J. Sci. Eng. 18, 852-860 (2018) 011303

26. Doğan, K., Karakaya, V:: On the convergence and stability results for a new general iterative process. Sci. World J. 2014 Article ID 852475 (2014)

27. Doğan, K., Karakaya, V.: A study in the fixed point theory for a new iterative scheme and a class of generalized mappings. Creative Math. Inform. 27(2), 151-160 (2018)

28. Ertürk, M., Gürsoy, F.: Some convergence, stability and data dependency results for a Picard-S iteration method of quasi-strictly contractive operators. Math. Bohem. 144(1), 69-83 (2019)

29. Fathollahi, S., Ghiura, A., Postolache, M., Rezapour, S.: A comparative study on the convergence rate of some iteration methods involving contractive mappings. Fixed Point Theory Appl. 2015, 234 (2015)

30. Fathollahi, S., Rezapour, S.: Efficacy of coefficients on rate of convergence of some iteration methods for quasi-contractions. Iran. J. Sci. Technol. Trans. A, Sci. 42(3), 1517-1523 (2018)

31. Fukhar-ud-din, H., Berinde, V: Iterative methods for the class of quasi-contractive type operators and comparison of their rate of convergence in convex metric spaces. Filomat 30(1), 223-230 (2016)

32. Garodia, C., Uddin, I.: Solution of a nonlinear integral equation via new fixed point iteration process. arXiv:1809.03771v1 (2018)

33. Garodia, C., Uddin, l.: A new fixed point algorithm for finding the solution of a delay differential equation. AlMS Math. 5(4), 3182-3200 (2020)

34. Garodia, C., Uddin, l.: A new iterative method for solving split feasibility problem. J. Appl. Anal. Comput. 10(3), 986-1004 (2020)

35. Gürsoy, F.: On Huang and Noor's open problem. arXiv:1501.03318v1 (2015)

36. Gürsoy, F:: A Picard-S iterative method for approximating fixed point of weak-contraction mappings. Filomat 30(10), 2829-2845 (2016)

37. Gürsoy, F., Eksteen, J.J.A., Khan, A.R., Karakaya, V.: An iterative method and its application to stable inversion. Soft Comput. 23(16), 7393-7406 (2019)

38. Gürsoy, F., Ertürk, M., Abbas, M.: A Picard-type iterative algorithm for general variational inequalities and nonexpansive mappings. Numer. Algorithms 83, 867-883 (2020)

39. Gürsoy, F., Karakaya, V.: A Picard-S hybrid type iteration method for solving a differential equation with retarded argument. arXiv:1403.2546v2 (2014)

40. Gürsoy, F., Khan, A.R., Ertürk, M., Karakaya, V.: Coincidences of nonself operators by a simpler algorithm. Numer. Funct. Anal. Optim. 41(2), 192-208 (2020)

41. Gürsoy, F., Khan, A.R., Fukhar-ud-din, H.: Convergence and data dependence results for quasi-contractive type operators in hyperbolic spaces. Hacet. J. Math. Stat. 46(3), 373-388 (2017)

42. Hussain, N., Chugh, R., Kumar, V., Rafiq, A.: On the rate of convergence of Kirk-type iterative schemes. J. Appl. Math. 2012, Article ID 526503 (2012)

43. Hussain, N., Kumar, V., Kutbi, M.A.: On rate of convergence of Jungck-type iterative schemes. Abstr. Appl. Anal. 2013, Article ID 132626 (2013)

44. Hussain, N., Rafiq, A., Damjanović, B., Lazović, R.: On rate of convergence of various iterative schemes. Fixed Point Theory Appl. 2011, 45 (2011)

45. Hussain, N., Ullah, K., Arshad, M.: Fixed point approximation of Suzuki generalized nonexpansive mappings via new faster iteration process. arXiv:1802.09888 (2018)

46. Jamil, Z.Z., Abed, M.B.: On a modified SP-iterative scheme for approximating fixed point of a contraction mapping Iraqi J. Sci. 56(4B), 3230-3239 (2015)

47. Kadioglu, N., Yildirim, l.: Approximating fixed points of nonexpansive mappings by a faster iteration process arXiv:1402.6530v1 (2014)

48. Kang, S.M., Ćirić, L.B., Rafiq, A., Ali, F., Kwun, Y.C.: Faster multistep iterations for the approximation of fixed points applied to Zamfirescu operators. Abstr. Appl. Anal. 2013, Article ID 464593 (2013)

49. Karahan, I., Ozdemir, M.: A general iterative method for approximation of fixed points and their applications. Adv. Fixed Point Theory 3(3), 510-526 (2013)

50. Karakaya, V., Atalan, Y., Dogan, K., Bouzara, N.E.H.: Some fixed point results for a new three steps iteration process in Banach spaces. Fixed Point Theory 18, 625-640 (2017)

51. Karakaya, V., Doğan, K., Gürsoy, F., Ertürk, M.: Fixed point of a new three-step iteration algorithm under contractive-like operators over normed spaces. Abstr. Appl. Anal. 2013, Article ID 560258 (2013)

52. Karakaya, V., Gürsoy, F., Ertürk, M.: Comparison of the speed of convergence among various iterative schemes, arXiv:1402.6080v1 (2014) 
53. Karakaya, V., Gürsoy, F., Ertürk, M.: Some convergence and data dependence results for various fixed point iterative methods. Kuwait J. Sci. 43(1), 112-128 (2016)

54. Khan, A.R., Gürsoy, F., Karakaya, V.: Jungck-Khan iterative scheme and higher convergence rate. Int. J. Comput. Math. 93(12), 2092-2105 (2016)

55. Khan, A.R., Kumar, V., Hussain, N.: Analytical and numerical treatment of Jungck-type iterative schemes. Appl. Math. Comput. 231, 521-535 (2014)

56. Knopp, K.: Theory and Applications of Infinite Series. Berlin (1931)

57. Kosol, S.: Strong convergence theorem of a new iterative method for weak contractions and comparison of the rate of convergence in Banach space. Adv. Fixed Point Theory 8(3), 303-312 (2018)

58. Kumam, W., Khammahawong, K., Kumam, P.: Error estimate of data dependence for discontinuous operators by new iteration process with convergence analysis. Numer. Funct. Anal. Optim. 40(14), 1644-1677 (2019)

59. Kumar, L.: On the fastness of the convergence between Mann and Noor iteration for the class of Zamfirescu operators. IOSR J. Math. 10(5), 48-52 (2014)

60. Kumar, N., Chauhan, S.S.: Analysis of Jungck-Mann and Jungck-Ishikawa iteration schemes for their speed of convergence. AIP Conf. Proc. 2050, 020011 (2018)

61. Kumar, N., Chugh, R.: On the convergence and stability of new hybrid iteration process in Banach spaces. Int. J. Appl. Eng. Res. 12, 2935-2944 (2019)

62. Kumar, V:: Comments on convergence rates of Mann and Ishikawa iterative schemes for generalized contractive operators. Int. J. Math. Anal. 7, 1317-1321 (2013)

63. Kumar, V., Latif, A., Rafiq, A., Hussain, N.: S-iteration process for quasi-contractive mappings. J. Inequal. Appl. 2013, 206 (2013)

64. Malik, T.A., Choudhary, M.A.: Approximation of fixed points for nonexpansive operators by means of the fastest Krasnoselskij iteration in Hilbert spaces. New Trends Math. Sci. 7(2), 188-201 (2019)

65. Mebawondu, A.A., Mewomo, O.T.: Fixed point results for a new three steps iteration process. Ann. Univ. Craiova Math. Comput. Sci. Ser. 46(2), 298-319 (2019)

66. Mogbademu, A.A.: New iteration process for a general class of contractive mappings. Acta Comment. Univ. Tartu Math. 20(2), 117-122 (2016)

67. Okeke, G.A.: Convergence analysis of the Picard-Ishikawa hybrid iterative process with applications. Afr. Math. 30(5-6), 817-835 (2019)

68. Okeke, G.A., Abbas, M.: A solution of delay differential equations via Picard-Krasnoselskii hybrid iterative process. Arab. J. Math. 6(1), 21-29 (2017)

69. Olaleru, J.O.: A comparison of Picard and Mann iterations for quasi-contraction maps. Fixed Point Theory 8(1), 87-95 (2007)

70. Olaleru, J.O.: On the convergence rates of Picard, Mann and Ishikawa iterations of generalized contractive operators. Stud. Univ. Babes-Bolyai, Math. 54(4), 103-114 (2009)

71. Öztürk Çeliker, F.: Convergence analysis for a modified SP iterative method. Sci. World J. 2014, Article ID 840504 (2014)

72. Pansuwan, A., Sintunavarat, W.: The modified Picard-FB iterative algorithm for approximating the fixed points of conditional quasi-contractive mappings in convex metric spaces and its rate of convergence. J. Math. Anal. 9(5), $55-66(2018)$

73. Phuengrattana, W., Suantai, S.: Comparison of the rate of convergence of various iterative methods for the class of weak contractions in Banach spaces. Thai J. Math. 11(1), 217-226 (2013)

74. Piri, H., Daraby, B., Rahrovi, S., Ghasemi, M.: Approximating fixed points of generalized $\alpha$-nonexpansive mappings in Banach spaces by new faster iteration process. Numer. Algorithms 81, 1129-1148 (2019)

75. Popescu, O.: Picard iteration converges faster than Mann iteration for a class of quasi-contractive operators. Math. Commun. 12(2), 195-202 (2007)

76. Prassad, B., Goyal, K.: Stability of Jungck-Noor iteration in b-metric space. Int. J. Control Theory Appl. 9(41), 1069-1079 (2016)

77. Qing, Y., Rhoades, B.E.: Letter to the editor: Comments on the rate of convergence between Mann and Ishikawa iterations applied to Zamfirescu operators. Fixed Point Theory Appl. 2008, Article ID 387504 (2008)

78. Rafiq, A., Lee, B.S., Damjanović, B., Djorić, D.: New three-step iteration process involving Zamfirescu operators. Nonlinear Anal. Forum 15, 153-162 (2010)

79. Rani, A., Jyoti, K.: A new K-step iterative scheme in convex metric space. IOSR J. Math. 12(3 Ver. II), 11-20 (2016)

80. Rhoades, B.E.: Comments on two fixed point iteration methods. J. Math. Anal. Appl. 56(3), 741-750 (1976)

81. Rhoades, B.E., Xue, Z.: Comparison of the rate of convergence among Picard, Mann, Ishikawa, and Noor iterations applied to quasicontractive maps. Fixed Point Theory Appl. 2010, Article ID 169062 (2010)

82. Sahu, D.R.: Applications of the S-iteration process to constrained minimization problems and split feasibility problems. Fixed Point Theory 12(1), 187-204 (2011)

83. Sahu, V.K., Pathak, H.K., Tiwari, R.: Convergence theorems for new iteration scheme and comparison results. Aligarh Bull. Math. 35(1-2), 19-42 (2016)

84. Sharma, A., Imdad, M.: Fixed point approximation of generalized nonexpansive multi-valued mappings in Banach spaces via new iterative algorithms. Dyn. Syst. Appl. 26, 395-410 (2017)

85. Sintunavarat, W: An iterative process for solving fixed point problems for weak contraction mappings. In: Proceedings of the International MultiConference of Engineers and Computer Scientists 2017 Vol II, IMECS 2017, March 15-17, 2017, Hong Kong, pp. 1019-1023 (2017)

86. Sintunavarat, W., Pitea, A.: On a new iteration scheme for numerical reckoning fixed points of Berinde mappings with convergence analysis. J. Nonlinear Sci. Appl. 9, 2553-2562 (2016)

87. Thakur, B.S., Thakur, D., Postolache, M.: A new iteration scheme for approximating fixed points of nonexpansive mappings. Filomat 30(10), 2711-2720 (2016)

88. Thakur, D., Thakur, B.S., Postolache, M.: New iteration scheme for numerical reckoning fixed points of nonexpansive mappings. J. Inequal. Appl. 2014, 328 (2014)

89. Thong, D.V.: The comparison of the convergence speed between Picard, Mann, Shikawa and two-step iterations in Banach spaces. Acta Math. Vietnam. 37(2), 243-249 (2012) 
90. Verma, M., Jain, P., Shukla, K.K.: A new faster first order iterative scheme for sparsity-based multitask learning. In: 2016 IEEE International Conference on Systems, Man, and Cybernetics (SMC) (2016)

91. Wahab, O.T., Rauf, K.: On faster implicit hybrid Kirk-multistep schemes for contractive-type operators. Int. J. Anal. 2016 Article ID 3791506 (2016)

92. Xue, Z:: The comparison of the convergence speed between Picard, Mann, Krasnoselskij and Ishikawa iterations in Banach spaces. Fixed Point Theory Appl. 2008, Article ID 387056 (2008)

93. Yadav, M.R.: Two-step iteration scheme for nonexpansive mappings in Banach space. Math. Morav. 19(1), 95-105 (2015)

94. Yildirim, l.: On the rate of convergence of different implicit iterations in convex metric spaces. Konuralp J. Math. 6(1), $110-116(2018)$

95. Yildirim, I., Abbas, M.: Convergence rate of implicit iteration process and a data dependence result. arXiv:1703.10357v1 (2017)

Submit your manuscript to a SpringerOpen ${ }^{\circ}$ journal and benefit from:

- Convenient online submission

- Rigorous peer review

- Open access: articles freely available online

- High visibility within the field

- Retaining the copyright to your article

Submit your next manuscript at $\gg$ springeropen.com 